\title{
ANÁLISE DO DISCURSO NA ÁREA DE LETRAS
}

\author{
Maria Teresinha Py Elichirigoity ${ }^{*}$
}

\begin{abstract}
RESUMO: Na Análise do Discurso, graças ao trabalho com a ideologia, entende-se a linguagem como produção social e o sujeito, como construção polifônica, historicamente constituído. Então, a AD, negando a transparência da linguagem, trabalha os processos de produção de sentido com base em determinações histórico-sociais, considerando as condições de produção como fatores regentes da interpretação. Mas a questão é saber em que nicho se coloca a AD, se é que isso é possível, ao mesmo tempo em que se discute a imparcialidade que o analista pretende e julga assumir.
\end{abstract}

PALAVRAS-CHAVE: Análise do Discurso - Ideologia - Condições de produção

ABSTRACT: In Discourse Analysis, due to its work with ideology, language is understood as a social production and the subject as a polyphonic, historically constituted construction. In denying language transparency, Discourse Analysis deals with the processes of meaning production based on social and historical determinations, considering the production conditions as dominating factors of the interpretation. Yet the question is to know where Discourse Analysis is placed - if this is possible - and, at the same time, to put in doubt the impartiality that the analyst intends and assumes as his own reality.

KEYWORDS: Discourse Analysis - Ideology - Production conditions

\section{PRINCÍPIO DE CONVERSA}

Este artigo pretende responder a estudantes iniciantes, que se vêem perdidos na densidade e amplitude teórica e bibliográfica, o que seja Análise do Discurso (AD) na área de Letras. À primeira vista, tal objetivo pode parecer simples e, para alguns especialistas da $\mathrm{AD}$, as questões, superadas. Por outro lado, como reconhece Orlandi (1986, p. 105), procurar definir o que é AD é “cair no engano do próprio objeto”. Teses sobre a língua, a enunciação, e a história embasam conjuntos de descrições e proposições que regulam a metodologia da $\mathrm{AD}$ e dão um sentido aos resultados que produzem. Nessa tarefa proposta - muito complexa, na verdade -, é indispensável traçar um percurso teórico bastante variado, recuperando aspectos históricos e comparando-os, a fim de que certos conceitos básicos sejam firmados, e consolidando noções importantes para a compreensão do que é $\mathrm{AD}$, visto que, aprisioná-la nas grades de um conceito seria o mesmo que impor limites ao universo dos discursos.

Mesmo assim, na ansiedade comum do pesquisador, além de averiguar as origens, busca-se logo dividir, classificar, localizar o fenômeno observado, ainda que dentro de nosso ângulo possível de visão, dos nossos limites. Que limites serão esses? Talvez, ao longo deste artigo, com a compreensão do que a própria $\mathrm{AD}$ é, eles sejam revelados.

\footnotetext{
* Mestre em Lingüística Aplicada pela UCPel e doutora na área de Teorias do Texto e do Discurso da UFRGS; professora adjunta do Curso de Letras da UCPel; e-mail: tereli@ucpel.tche.br.
} 
Em Nota do Leitor, escrita por Eni Orlandi em sua tradução do trabalho de Pêcheux (1977, p.7-9) tem-se uma noção clara sobre o lugar da Análise do Discurso no campo das ciências. Diz a autora, nessa Nota, que a AD proposta por Pêcheux é uma forma de reflexão sobre a linguagem que "não aceita o desconforto de se ajeitar e no lugar já feito" e que seus "princípios teóricos não se alojam em regiões já categorizadas do conhecimento, mas em intervalos da articulação contraditória das disciplinas". Então, fica, desde já, evidenciado que não é fácil o desafio de definir e localizar a AD.

A AD é um processo de desconstrução, construção e compreensão incessante de seu objeto: o discurso. Com isso, coloca questões para várias disciplinas, interessandose pelos efeitos de certeza que esses conhecimentos produzem, fazendo a história de suas ciências. A AD - dispositivo de análise ou instauração de novos gestos de leitura leva em conta o confronto do contato do histórico com o lingüístico, que constitui a materialidade específica do discurso. Como Pêcheux refletiu, além da questão do marxismo, há também o caráter de interpretação de história, que aparenta o movimento de interpretação do homem diante dos fatos. Por isso, a história está colocada. Então a $\mathrm{AD}$ trabalha justamente no lugar desse aparentar, criando um espaço teórico em que se pode produzir o descolamento dessa relação, desterritorializando-a.

Neste artigo, além de ser delineado o quadro epistemológico da $\mathrm{AD}$ em que se desenvolve o processo de formação do discurso, são traçadas as diferenças conceituais entre discurso e texto; entre funcionamento lingüístico e funcionamento discursivo; entre as práticas discursivas de leitura e de textualização. E, a partir da análise de cada fase da $\mathrm{AD}$, observa-se que os conceitos vão tomando novos matizes, como ocorreram com as formas de interpelação do sujeito.

Então - após o grande divisor de águas dos estudos lingüísticos, o corte saussureano com sua posição teórica de oposição língua/fala, na qual Saussure privilegiou o dentro da língua por se constituir em fenômenos mais controláveis e possíveis de descrição, a AD coloca como ruptura outro conceito - o conceito de discurso. E para que se compreenda como a $\mathrm{AD}$ entende discurso, é preciso uma visão, ainda que rápida, sobre como Pêcheux (1975) embasa sua Análise Automática do Discurso.

\section{QUADRO EPISTEMOLÓGICO DA AD}

O quadro epistemológico geral da análise automática do discurso (AAD) reside em três regiões do conhecimento, articuladas por uma teoria da subjetividade (de natureza psicanalítica): (i) o materialismo histórico, como teoria das formações sociais e de suas transformações (inclusive a teoria das ideologias); (ii) a lingüística, como teoria dos mecanismos sintáticos e dos processos de enunciação ao mesmo tempo; e (iii) a teoria do discurso, como a teoria da determinação histórica dos processos semânticos.

Para Orlandi (1986, p. 123), a AD não tem limites estritamente marcados, mas abrange desde análises discursivas de mecanismos lingüísticos precisos (por exemplo, o uso do se como forma de indeterminação na linguagem) até usos lexicais ou mecanismos enunciativos, como os que caracterizam o discurso polêmico e o didático, ou a distinção de tipos de discurso (como o científico e o jornalístico), ou de processos discursivos mais abrangentes ou ainda, análises sobre conceitos, como sujeito, texto, leitura... 
Pêcheux foi o primeiro a dar uma certa organização teórica nesse campo de estudos. Em A propósito da Análise Automática do Discurso (AAD), Pêcheux e Fuchs (1975), na segunda parte, preparam o terreno para a superação do atraso no nível dos procedimentos práticos de tratamento dos textos em comparação ao nível atingido nas discussões sobre a relação entre as três regiões mencionadas anteriormente e, antes de tudo, pretendem reduzir a distância entre a análise de discurso da teoria do discurso. Abriu-se, assim, a perspectiva para uma forma de conhecimento que atualmente se desenvolve graças a estudos que têm, como ponto comum, pensar a significação, a língua e a ideologia, reintroduzindo a história na (pela) reflexão sobre a linguagem.

Pêcheux e Fuchs (1975, p.165) apontam para alguns mascaramentos, nas universidades, das teorias do quadro epistemológico da AAD: (i) o materialismo histórico (superestrutura ideológica em sua ligação com o modo de produção que domina a formação social considerada) se transforma em sociologia; e (ii) à teoria do discurso se reserva o aspecto social da linguagem.

Principalmente de acordo com o pensamento de Althusser, em sua obra original de 1970, Ideologia e Aparelhos Ideológicos do Estado, a região da ideologia caracterizase por uma materialidade específica, articulada sobre a materialidade econômica que determina o funcionamento da instância ideológica, a qual, por sua vez, aparece como uma das condições da reprodução das relações de produção inerentes a essa base econômica, ou seja, o assujeitamento do sujeito como sujeito ideológico (interpelação). Essa reprodução contínua de relações de classe é assegurada materialmente, segundo Althusser (1996, p. 105-40), por "aparelhos ideológicos do Estado", que colocam em jogo práticas associadas a relações de lugares que remetem às relações de classes, sem decalcá-las exatamente. Num dado momento histórico a luta de classes se caracteriza pelo afrontamento, no interior mesmo desses aparelhos que mantêm entre si relações de antagonismo, aliança ou dominação. Esse aspecto de luta nos aparelhos é denominado de formação ideológica e constitui um conjunto complexo de atitudes e representações que não são nem individuais nem universais. A formação ideológica relaciona-se diretamente a posições de classes em conflito umas com as outras.

As formações ideológicas, por sua vez, comportam necessariamente, como um de seus componentes, uma ou várias formações discursivas interligadas que determinam o que pode e deve ser dito, a partir de uma posição dada numa conjuntura (no interior de um aparelho ideológico e inscrita numa relação de classes). Daí, toda formação discursiva (FD) derivar de condições de produção específicas.

Entende-se como condição de produção, conforme Orlandi (2001, p. 30): em sentido estrito, como circunstâncias da enunciação, ou seja, trata-se do contexto imediato; e, em sentido amplo, como contexto sócio-histórico e ideológico. Ferreira (2001, p. 13) lembra que as condições de produção fazem parte da exterioridade da língua e são responsáveis pelo estabelecimento das relações de força no interior do discurso, mantendo com a linguagem uma relação necessária, pois constituem, com ela, o sentido do texto.

Uma formação discursiva existe historicamente no interior de determinadas relações de classes; e pode fornecer elementos que se integrem em novas formações discursivas, constituindo-se no interior de novas formações ideológicas. A dificuldade teórica surge quando se pretende criar limites: como caracterizar as fronteiras reais entre formação ideológica, formação discursiva e condições de produção?

Quantas formações ideológicas existem em uma formação social? Quantas formações discursivas cada uma delas pode conter? Os teóricos marxistas sabem que 
uma discretização de tal ordem é impossível devido ao caráter dialético dessas realidades, o que, por outro lado, compromete o seu caráter discreto (ou seja, o que é distinto). Então, o ponto da exterioridade relativa de uma formação ideológica (FI) em relação a uma formação discursiva (FD) se traduz no próprio interior dessa formação discursiva: ela designa o efeito necessário de elementos ideológicos não-discursivos (representações, imagens ligadas a práticas etc.) numa determinada formação discursiva. Caracteriza-se como esquecimento $n^{\circ} 1$ (inerente à prática subjetiva ligada à linguagem) a defasagem entre a primeira formação discursiva (matéria-prima representacional) e uma outra em que a discursividade da primeira parece se esvanecer aos olhos do sujeito falante.

Isso significa que há uma matriz do sentido e que a produção do sentido é estritamente indissociável da relação de paráfrase. Então, a evidência da leitura subjetiva segundo a qual um texto é biunivocamente associado ao seu sentido (com ambigüidades sintáticas e/ou semânticas) é uma ilusão constitutiva do efeito sujeito em relação à linguagem: o sentido de uma seqüência só é materialmente concebível se essa seqüência é inserida numa formação discursiva (efeito de assujeitamento), ou noutra (o que possibilita os vários sentidos de uma seqüência). Assim, toda seqüência pertence, necessariamente, a uma FD para que tenha sentido o qual se acha recalcado pelo sujeito, e recoberto pela ilusão de estar na fonte do sentido, sob a forma de retomada pelo sujeito de um sentido universal preexistente (ilusão discursiva do sujeito do eterno par subjetividade/universalidade).

A AAD, portanto, ao adequar-se às teorias do discurso explicitadas, não pode admitir a análise semântica de $u m$ texto. Considerando processos discursivos como relações de paráfrases interiores à matriz do sentido inerente à formação discursiva, o procedimento da $\mathrm{AAD}$ constitui o esboço de uma análise não subjetiva dos efeitos de sentido que atravessa a ilusão do efeito sujeito (produção/leitura) e que retorna ao processo discursivo por uma espécie de arqueologia regular. Portanto, os processos discursivos não têm sua origem no sujeito, mas se realizam no sujeito porque ele é assujeitado.

Segundo Pêcheux (1997, p. 171), o que falta, parcialmente, é uma teoria nãosubjetiva da constituição do sujeito em sua situação concreta de enunciador. O sujeito, mesmo sendo considerado uma ilusão, é necessário e impõe a tarefa de descrição de sua estrutura (esboço descritivo da enunciação), assim como a articulação da descrição desta ilusão que foi chamada de esquecimento $n .^{\circ} 1$. Assim, apesar de toda essa abstração teórica, a AAD tem por objetivo a análise não subjetiva dos efeitos de sentido. Como pode ser isso?

\section{A LINGÜÍSTICA COMO TEORIA DOS MECANISMOS SINTÁTICOS E DOS PROCESSOS DE ENUNCIAÇÃO}

Evidenciando os traços dos processos discursivos, a AAD comporta uma fase de análise lingüística, o que exige uma definição prévia da natureza e do papel que se atribui à língua. Do ponto de vista da teoria do discurso, os processos discursivos estão na fonte da produção dos efeitos de sentido e a língua constitui o lugar material onde se realizam esses efeitos de sentido. Embora seja insuficiente conceber a língua como a base de um léxico e de sistemas fonológicos, morfológicos e sintáticos, nessas condições, a tarefa do lingüista consistiria em caracterizar e em tornar operacionalmente 
manipuláveis este léxico e este sistema de regras, evitando-se de aí fazer intervir considerações semânticas incontroladas (cair no efeito subjetivo da leitura).

Objetivando a análise não-subjetiva dos efeitos de sentidos, a AAD passa então por uma fase de análise lingüística essencialmente morfossintática e em que se procura definir, afinal, o papel da semântica. Apresentada em sua forma extrema, a posição lingüística inerente à $\mathrm{AAD}$ voltaria a considerar que sintaxe e semântica constituem dois níveis autônomos e bem definidos e que léxico e gramática são igualmente dois domínios distintos. Mas Pêcheux (1975, p. 173) acha que isso não é assim, pois, longe de se evitar qualquer contaminação da análise lingüística pela semântica, as regras sintáticas aplicadas introduzem, sub-repticiamente, recursos não-controlados ao sentido. E conclui que falta uma teoria do funcionamento material da língua que se articule em processos com o não-sistemático.

A teoria desse funcionamento material da língua poderia chamar-se semântica formal e ela não coincide com a semântica discursiva. A semântica formal seria o último nível da análise lingüística e atingiria, nesse sentido, o lugar específico da língua, que corresponde à construção do efeito-sujeito. A AAD deveria aferir onde ela atravessa o efeito-sujeito. Isso traz à tona a questão da enunciação.

O estudo das marcas da enunciação deve constituir um ponto central da fase de análise lingüística da $\mathrm{AAD}$, o que induz a modificações importantes na concepção da língua, quais sejam: (i) o léxico não é uma simples lista de morfemas, mas um conjunto estruturado de elementos articulados sobre a sintaxe; e (ii) a sintaxe não é o domínio neutro de regras formais, mas o modo de organização (próprio de determinada língua) dos traços das referências enunciativas. As construções sintáticas, desse ponto de vista, têm, pois, uma significação que convém destacar.

Se a enunciação pressupõe sujeito enunciador com o seu enunciado, então, aparece no próprio nível da língua uma nova ilusão segundo a qual o sujeito se encontra na fonte do sentido ou se identifica à fonte do sentido: o discurso do sujeito se organiza por referência (direta, divergente) ou ausência de referência, à situação de enunciação (o eu-aqui-agora do locutor) que ele experimenta subjetivamente como tantas origens quantos são os eixos de referenciação (eixos das pessoas, dos tempos, das localizações). Toda a atividade de linguagem necessita da estabilidade desses pontos de ancoragem para que não haja um abalo na estrutura do sujeito e da própria linguagem.

Pêcheux (ibid., p. 175) critica as teorias da enunciação que se contentam em reproduzir no nível teórico a ilusão do sujeito através da idéia de um sujeito enunciador portador de escolha, intenções, decisões, etc., como se vê em Bally (1940), Jakobson (1963) e Benveniste (1966). Pêcheux entende que os processos de enunciação consistem em uma série de determinações sucessivas pelas quais o enunciado se constitui pouco a pouco e que tem por característica colocar o dito e, em conseqüência, rejeitar o nãodito. A enunciação equivale a colocar fronteiras entre o que é selecionado e tornado preciso aos poucos (o universo do discurso) e o que é rejeitado - espaço vazio em que se desenha tudo que seria possível ao sujeito dizer, mas não diz (ou tudo que se opõe ao que o sujeito diz). Essa zona do rejeitado pode estar mais ou menos próxima da consciência e na interlocução, com o intuito de ser mais preciso, o sujeito pode reformular as fronteiras e re-investigar essa zona. Esse efeito de ocultação parcial é chamado de esquecimento $n^{\circ} 2$ e se identifica aí a fonte de impressão da realidade do pensamento para o sujeito (eu sei o que eu digo, eu sei o que eu falo).

Constata-se que, na enunciação, o sujeito pode penetrar conscientemente na zona do esquecimento $\mathrm{n}^{\mathrm{o}} 2$ e que ele o faz constantemente por um retorno de seu discurso 
sobre si, uma antecipação de seu efeito, e pela consideração da defasagem que aí introduz o discurso de um outro. A zona do $\mathrm{n}^{\mathrm{o}} 2$, que é a dos processos de enunciação, se caracteriza por um funcionamento do tipo pré-consciente/consciente. Por oposição, o esquecimento $n^{\circ} 1$ cuja zona é inacessível ao sujeito, precisamente por essa razão, aparece como constitutivo da subjetividade na língua. $\mathrm{O}$ esquecimento $\mathrm{n}^{\mathrm{o}} 1$ se articula com o interdiscurso por relações de contradição, submissão ou de usurpação e é de natureza inconsciente, no sentido em que a ideologia é constitutivamente inconsciente dela mesma. Para usar termos lacanianos, o recalque do esquecimento $\mathrm{n}^{\mathrm{o}} 1$ (refere-se à ideologia, à formação discursiva...) regula a relação entre o dito e o não-dito no esquecimento $\mathrm{n}^{0} 2$ que estrutura a seqüência discursiva na enunciação.

A memória, pensada em relação ao discurso é tratada como interdiscurso. Em outras palavras, interdiscurso é aquilo que fala antes, em outro lugar, independentemente; é a memória discursiva, ou seja, forma do pré-contruído, o já dito que está na base do dizível, sustentando cada tomada de palavra. Logo, o interdircurso disponibiliza dizeres que afetam o modo como o sujeito significa em uma situação discursiva dada. O dizer não é propriedade particular. As palavras significam pela história e pela língua. $\mathrm{O}$ que é dito em outro lugar também significa nas nossas palavras.

Então, para Pêcheux, o termo discurso não pode ser considerado como fala (que escapa ao sistema), nem como um suplemento social do enunciado (um elemento particular do sistema da língua). Pêcheux invoca a distinção entre base lingüística e processo discursivo (que se desenvolve sobre essa base), distinção essa que, segundo ele, pode autorizar a consideração das relações de contradição, antagonismo, aliança, absorção... entre formações discursivas que pertencem a formações ideológicas diferentes, sem implicar a existência mítica de uma pluralidade de línguas, pertencentes a estas formações.

\section{OBJETO E UNIDADE NA AD: O DISCURSO E O TEXTO}

Considera-se que o discurso é a linguagem em interação, a linguagem em suas condições de produção, ou seja, a relação estabelecida pelos interlocutores, assim como o contexto são constitutivos da significação do que se diz. Com essa noção de discurso estabelece-se que o modo de existência da linguagem é social e fica entre a língua (geral) e a fala (individual): o discurso é o lugar social. Daí poder-se considerar a linguagem como trabalho.

Com base em Pêcheux, Orlandi (1987, p.158), afirma que essas condições de produção são formações imaginárias que contam com relações de forças (os lugares sociais dos interlocutores e sua posição relativa no discurso), com a relação de sentido (o coro de vozes, a intertextualidade, a relação que existe entre um discurso e os outros) e a antecipação (entre os interlocutores).

O sujeito falante produz linguagem e também está reproduzido nela; assim, ao mesmo tempo em que acredita ser a fonte exclusiva de seu discurso - ilusão subjetiva constitutiva do sujeito falante - seu dizer tem origem em outros discursos. Na AD, podem-se observar palavras, frases e períodos, sem que essas unidades percam sua especificidade de nível lexical, morfológico, sintático e semântico, mas a perspectiva incidirá sobre aspectos discursivos dessas unidades. Portanto, o objeto da AD é o discurso e sua unidade é o texto. 
Para definir a relação discurso versus texto, observa-se, primeiramente, que o conceito de discurso é teórico e metódico, enquanto o de texto é um conceito analítico. Portanto, se o texto é visto como correspondência à perspectiva teórica de um discurso, ele não é apenas a unidade de análise, mas a unidade complexa de significação, consideradas suas condições de realização. O texto, então, é uma unidade de análise pragmática que pode ter qualquer extensão, pois o que o define é sua unidade de significação em relação à situação.

O texto no processo de interlocução é a unidade que se faz no processo de interação entre falante e ouvinte, sendo parcial o domínio de cada um deles e a interação só tem a unidade no/do texto. Essa unidade do processo de significação é a totalidade da qual se parte na análise de estruturação do discurso.

Lembrando Voloshinov (1976), Orlandi (1987, p.159) diz que "o texto é o enunciado como entidade total" e que "a noção de discurso acolhe essa entidade". O diálogo, interação entre os interlocutores, por sua vez, e a relação dialógica são básicos para a caracterização da linguagem: "o conceito de discurso se assenta sobre a relação dialógica, na medida em que é constituído pelos interlocutores". Assim, de acordo com a relação estabelecida entre os interlocutores, haverá diferentes espécies de textos: uma palestra, uma aula, uma conversa informal.

A idéia de diálogo está na base de qualquer reflexão sobre linguagem, desde que vista como um processo cujo uso é reflexo da situação social. Assim, todo texto é dialógico e constituído por um discurso, mas essa noção se distingue de conversa, debate, sermão, etc. que são gêneros (situações particulares de discurso/texto/diálogo).

O texto é um espaço simbólico não fechado em si mesmo: tem relação com o contexto e com os outros textos. A isso se denomina intertextualidade, um dos fatores que constituem a unidade do texto e que pode ser vista tanto como relação de um texto com outros dos quais ele nasce (sua matéria prima) ou para os quais aponta (seu futuro discursivo) ou, ainda, paráfrases.

Por outro lado, nos turnos de uma conversa, não há sucessão linear, mas simultaneidade - não há um limite claro que separe o dizer de um do dizer de outro, nem há segmentos que se juntem linearmente para formar uma unidade maior. Então a linguagem tem como condição a incompletude e seu espaço é intervalar nas duas dimensões: a dos interlocutores e a da seqüência dos segmentos. O sentido é intervalar porque está no espaço discursivo e não em um ou outro interlocutor, nem em um segmento ou outro ou ainda na soma dos segmentos que constituem um texto determinado. O sentido está na unidade a partir da qual os recortes se organizam. Prefere-se o termo recorte (que remete à situação de interlocução) ao termo segmento (domínio do distribucionalismo), porque esse campo teórico relaciona-se à ideologia que acarreta um domínio de indeterminação na constituição da unidade textual. Portanto, o conceito de texto, uma unidade de significação, não implica o conceito de completude. Já se falou sobre as condições de produção do discurso. Serão as do texto as mesmas?

As condições de produção de um texto dizem respeito tanto ao locutor quanto ao receptor: na escrita já está inscrito o leitor e, na leitura, o leitor interage com o autor do texto. Pela definição pragmática de texto como o lugar, o centro comum que se faz no processo de interação entre falante $\mathrm{x}$ ouvinte, escritor $\mathrm{x}$ leitor, vê-se que essa bipolaridade contraditória só encontra sua unidade no texto. Pensando-se o texto como unidade complexa de significação (devido às suas condições de realização), pode-se 
observar que o texto, considerado como objeto teórico, é uma unidade incompleta, pois sendo de natureza intervalar, seu sentido está no espaço discursivo dos interlocutores.

Por outro lado, pode-se considerar o texto como um objeto empírico (superfície lingüística), com princípio, meio e fim e, nesse caso, o texto pode ser um objeto acabado (um produto). Mas a AD reinstala, no domínio dos limites do texto, enquanto objeto empírico, suas condições de produção, o que lhe devolve sua incompletude.

Como já foi dito anteriormente, para conhecer o funcionamento do discurso (que não é integralmente lingüístico, precisa-se levar em consideração suas condições de produção, o que remete à sua exterioridade - contexto de enunciação e contexto sóciohistórico. Isso mostra o texto em sua incompletude, pois o sentido de um texto está nas margens dos enunciados efetivamente realizados e essa margem é um espaço determinado pelo social, o que permite uma multiplicidade de sentidos. Daí os implícitos - pressupostos e subentendidos-, em especial os derivados da intertextualidade, serem reveladores da incompletude.

Para Pêcheux, o processo discursivo não tem, de direito, um início: o discurso se estabelece sempre sobre um discurso prévio (relação de sentidos). A noção de intertextualidade também é composta pela relação de um texto com outros textos que poderiam ter sido produzidos em determinadas condições e que não o foram, embora ocupem o espaço de discursividade. Estaria aí incluída a relação de forças, pela qual se liga o locutor ao lugar social do qual diz. Ele diz o que pode.

Então, a noção complexa de intertextualidade, a relação de forças, os implícitos fazem parte da relação de interação que a leitura estabelece. Considerar as condições de produção da leitura é trabalhar, fundamentalmente com essa indeterminação: a incompletude do texto.

Considerando essa incompletude, o texto, no entanto, não pode ser considerado uma matriz com lacunas que são preenchidas pelo leitor, pois a natureza da incompletude não é lacunar, mas intervalar, derivada de suas condições de produção, ou seja, da relação com a situação e com os interlocutores. O texto é incompleto porque o discurso instala o espaço da intersubjetividade (constituída pela relação de interação). Assim, o texto não é o lugar de informações - completas ou a serem preenchidas -, mas é processo de significação, lugar de sentidos. Na leitura:

-Partimos da aparente determinação do texto como produto. Ponto de vista do texto como objeto acabado;

-Recuperamos o processo que o indetermina. Ponto de vista das condições de produção;

-Pousamos provisoriamente na determinação. Contexto específico, leitor específico, modo específico de leitura;

-Retornamos para a indeterminação, que é o confronto com o autor. Produto que se repõe como processo, outras leituras.

Do ponto de vista do texto como objeto acabado, chegaremos a uma leitura determinada, enquanto o percurso do plano de vista das condições de produção nos levará à possibilidade de várias leituras. 


\section{COMPARAÇÃO DAS DIFERENÇAS ENTRE FUNCIONAMENTO LINGÜÍSTICO E DISCURSIVO}

Por tudo que se viu até aqui, evidencia-se que a relação constitutiva entre o discurso e sua exterioridade é a marca fundamental da AD. Nessa relação reside a possibilidade mesma de se encontrarem regularidades no domínio discursivo. $\mathrm{Na}$ verdade, a relação entre a Lingüística e a $\mathrm{AD}$ é tensa, pois, embora a $\mathrm{AD}$ pressuponha a Lingüística (o que lhe dá especificidade em relação às metodologias de tratamento da linguagem nas ciências humanas), vê o texto como monumento, contrapondo-se à análise de conteúdo clássica que vê o texto como documento. Então, a AD é crítica com relação à análise de conteúdo e sua fundamentação teórica supõe a interferência de conceitos exteriores ao domínio da Lingüística imanente.

Indursky (1997), por exemplo, mostra como o processo de anaforização pode contrastar se visto sob o ângulo de seu funcionamento lingüístico ou de seu funcionamento discursivo, distinguindo, então, o processo semântico de retomada/repetição no âmbito do texto e do discurso. Enfatiza, no entanto, que, qualquer que seja o ângulo (frasal, textual ou discursivo), é indispensável a interpretação da referência dos elementos envolvidos na anaforização. Para a autora, o funcionamento lingüístico da anáfora pode não coincidir com seu funcionamento discursivo, constituindo-se esse processo num espaço teórico-analítico privilegiado para refletir sobre as relações que a forma material do discurso estabelece com a exterioridade, embora reconheça que há outros processos lingüísticos, além da anáfora, em que se estudam pistas desse funcionamento. Entre outros teóricos, Indursky (ibid., p. 715) cita o conceito de Milner (1983): "Há relação de anáfora entre duas unidades A e B quando a interpretação de $\mathrm{B}$ depende crucialmente da existência de $\mathrm{A}$, ao ponto de se poder dizer que a unidade $\mathrm{B}$ só é interpretável à medida que ela retoma - inteira ou parcialmente- a unidade A". Com esse conceito ancora-se a anáfora à sintaxe, assim como a noção de referência está na base da noção de anáfora. Como exemplo, lemos em Indursky (ibid., p. 715, grifos da autora): "Ruth Cardoso(A) declarou ser favorável à reeleição para o cargo de presidente, mas foi impossível fazê-la (B) posicionar-se sobre a eventual volta de seu marido".

Nesse caso, Ruth Cardoso (A) é uma referência exofórica (remete para a exterioridade, pois é preciso que se saiba quem é Ruth Cardoso - esposa do presidente do Brasil, na época); já o pronome oblíquo $a$ (B) é uma referência endofórica (identidade referencial com $\mathrm{A}$ - dentro do texto).

Continuando suas observações, Indursky (ibid., p. 716) cita Halliday e Hasan (1976) que deslocam a reflexão da frase para o texto - entendido por eles como "uma unidade da linguagem em uso, não uma unidade gramatical, como a oração ou a frase". O texto, para eles, é uma unidade semântica, não de forma, mas de significação. Portanto, a coesão textual, construída pelas relações anafóricas, é estudada na lingüística textual, baseada em análises de referência e correferenciação, desenvolvidas pela lingüística frasal. Segundo Indursky (ibid., p.718 ), a passagem da frase para o texto apenas amplia o objeto que a lingüística já havia determinado anteriormente, mantendose os pressupostos. A autora, para tecer sua argumentação, cita outros lingüistas, tais como Marchuschi (1983, p. 17), para quem a anáfora tem seu enfoque deslocado da sintaxe frasal para uma semântica da sintaxe textual e as relações tornam-se imanentes ao texto e não à língua, simplesmente - a lingüística textual estabelece o primado da superficie textual e o lingüista passa a perceber novas coerções. Porém, lembra Indursky 
(ibid., p. 717), segundo Jakobson, "na combinação das frases em enunciados, a ação das regras coercitivas da sintaxe termina e a liberdade do locutor cresce substancialmente".

Indursky critica essa concepção de liberdade, pois existem regras atuantes no nível textual que são igualmente coercitivas. Segundo a autora, a noção de textualidade ancorada na coerção textual corresponde à noção de gramaticalidade por sua vez, ancorada na coerção frasal e cita Marchuschi (1983, p. 31), para quem "as pronominalizações sempre correferem elementos da estrutura do texto, nunca entidades não recobráveis nesta estrutura", ou seja, ele quer dizer que a anáfora pronominal impõe a referência endofórica como a única possibilidade para a sua interpretação, conclui Indursky (1997, p.717).

Mas Indursky quer checar essa identidade referencial, fazendo intervir na análise, outros elementos que estabelecem relação entre o texto e a exterioridade. Instaura-se uma nova ordem a partir da qual é preciso contemplar de modo indissolúvel as relações internas e externas e com essa passagem será possível refletir sobre a anáfora discursiva.

O analista de discurso contrasta com a atitude metodológica do lingüista por não se colocar frente à frase ou ao texto para segmentá-lo, mas frente a uma seqüência discursiva para recortá-la, e submete à análise um recorte discursivo e não uma frase ou um texto. Isso significa que [seqüências discursivas + condições de produção] são constitutivos do recorte, que é um fragmento da situação discursiva. Então, o analista prioriza as relações do intradiscurso com a exterioridade - ou seja, com o interdiscurso. Esse é o domínio da anáfora discursiva.

Portanto, o recorte leva em conta o funcionamento discursivo, que é de natureza social, e onde os interlocutores e seus lugares sociais, juntamente com o contexto histórico social, já se colocam como constitutivos da relação de interlocução e do sentido que por meio dessa concepção se instaura.

O funcionamento discursivo engloba ainda, segundo Pêcheux (1969) as formações imaginárias - resultantes de um trabalho discursivo constitutivamente ideológico - que determinam não apenas os interlocutores, mas também os referentes. Portanto, a anáfora discursiva representa um pré-construído, tal como formulado por Pêcheux (1975) e outros.

Em síntese, comparando, pode-se dizer que no funcionamento lingüístico, a anáfora textual recupera "um dito presente na superfície textual" (no contexto anterior esquerdo), enquanto no funcionamento discursivo, a anáfora discursiva retoma um "jádito presente no interdiscurso específico do discurso em questão"(Indursky, p.721).

A pronominalização exofórica, por sua vez, representa um ponto de passagem da continuidade textual para a descontinuidade discursiva existente entre o texto e seu interdiscurso. É um vestígio do contato do texto com a exterioridade e essa passagem marca uma ruptura fundamental entre o texto e o discurso. Portanto, a anáfora está na base da coesão textual e discursiva, embora atue de forma diversa em cada um deles.

\section{A PRÁTICA DISCURSIVA DE TEXTUALIZAÇÃO E DE LEITURA A PARTIR DA HETEROGENEIDADE DO DISCURSO E DA INTERPELAÇÃO DO SUJEITO}

O texto, que representa a materialidade lingüística através do qual se tem acesso ao discurso, é uma unidade de análise afetada pelas condições de sua produção, a partir 
da qual se estabelecerá a prática da leitura. Para a $\mathrm{AD}$, a organização interna do texto pouco interessa. $\mathrm{Na} \mathrm{AD}$ o texto é um espaço simbólico cujo fechamento é um mero efeito. Fazem parte de sua constituição as relações contextuais, textuais e interdiscursivas. Daí ser o texto um espaço discursivo heterogêneo.

Indursky (2001, p. 30) observa que, embora seja o texto um espaço discursivo heterogêneo, no momento em que ele é produzido, surge um sujeito interpelado ideologicamente e identificado com uma posição-sujeito inscrita numa formação discursiva (o sujeito produz o seu texto a partir de um lugar social e passa, então, a sujeito-autor). Ele constrói um efeito de textualidade, apagando as marcas de exterioridade, heterogeneidade e dispersão e decorre disso o efeito de homogeneidade do texto.

As palavras já-ditas, ao serem apropriadas pelo sujeito-autor, são atravessadas pelo esquecimento para que ressoem como novas no interior do texto que está sendo produzido. O texto se apresenta como uma peça de linguagem dotada de completude (início, meio e fim) - é o ilusório efeito-texto. Assim, o fechamento instaura a ilusão de estabilização dos sentidos - decorre daí o efeito de consistência de que fala Courtine, lembra Indurky (ibid., p. 33).

Por outro lado, o sujeito autor é afetado pelo imaginário (graças ao esquecimento $\mathrm{n}^{\mathrm{o}}$ 2, segundo Pêcheux, conforme o explicitado anteriormente neste artigo), e supõe-se a fonte única de seu dizer. Cria-se o efeito de evidência - os sentidos são o que seu autor pretendeu que fossem. Dessa ilusão, o sujeito-autor emerge como efeito-sujeito.

Cabe, agora, reconsiderando, perguntar como se processa a leitura sobre um texto que é uma heterogeneidade estruturada, da qual decorre o efeito texto. Para responder, é preciso, em primeiro lugar, saber quem é o leitor.

Assim como o sujeito-autor (que escreve), o leitor é um sujeito interpelado ideologicamente, identificado dentro de uma formação discursiva. Portanto, o sujeitoleitor vai ocupar uma posição-sujeito em relação àquela ocupada pelo sujeito-autor, identificando-se ou não com ela. Então, o leitor instaura a prática discursiva da leitura.

A história de leitura pessoal do leitor vai determinar sua maior ou menor interação com a interdiscursividade constitutiva do efeito-texto a ser lido. E desse espaço simbolicamente fechado, o leitor extrai implícitos, pressupostos e subentendidos, promovendo a desconstrução do efeito-texto, desestabiliza a superfície homogênea. Decorre daí o aparecimento de um espaço discursivo fortemente lacunar e, segundo Indursky (ibid., p. 38), o sujeito-leitor desestabiliza o efeito de transparência e aparece o efeito de inconsistência.

Portanto, o resultado do trabalho discursivo da produção de leitura desestabiliza os sentidos que parecem estabilizados, podendo mesmo levá-los ao deslocamento, à deriva, à ruptura (contra-identificação ou desidentificação com os sentidos produzidos pelo sujeito-autor). Resumindo, a prática discursiva da leitura consiste em um intenso trabalho de desestruturação/estruturação, desestabilizando sentidos que parecem estar estabilizados - surge, assim, um novo efeito-texto com seus possíveis efeitos de sentido, mergulhado num processo histórico e, inevitavelmente, interdiscursivo.

Assim, os conceitos da $\mathrm{AD}$, à medida que as análises se aprofundam e se entrecruzam com outras áreas do saber, embora se mantenham fiéis a alguns postulados basilares, também vão se modificando. Parece, então, oportuno recordar de forma breve e mais sistematizada os três momentos da AD. 


\section{OS TRÊS MOMENTOS DA AD}

A concepção de discurso como máquina discursiva marcou o primeiro momento da $\mathrm{AD}$, quando se julgavam os discursos relacionados apenas por justaposição e Pêcheux acreditava na possibilidade de o discurso ser o elemento teórico da manifestação do assujeitamento do sujeito.

Já num segundo momento, a AD, influenciada pelas idéias de formação discursiva de Foucault passa a considerar as máquinas discursivas como constitutivamente invadidas umas pelas outras e não mais, portanto, um simples efeito de justaposição. Pêcheux questiona então a identidade da formação discursiva e a própria FD, tendo em vista seus limites tão tênues. Tal problema dá impulso a um novo momento na $\mathrm{AD}$.

É a terceira fase que corresponde ao primado teórico do outro sobre o mesmo. Pêcheux (1997) critica a AD que, ao mesmo tempo em que permitia desmontar a idéia do sujeito pleno, senhor da linguagem e do sentido, o prendia em uma rede de discursos que o sufocava, que não permitia sua irrupção. O discurso, preso nas malhas da estrutura, coloca no sujeito a máscara de uma história que o deixa imobilizado, incapaz de respirar, incapaz de fazer intervir suas marcas no próprio curso do discurso.

Essas amarras, compreensíveis na primeira fase devido ao próprio momento histórico do surgimento da $\mathrm{AD}$, precisavam ser superadas, para que se pudesse perceber melhor o aparecimento do acontecimento na estrutura, da singularidade na regularidade, do outro no mesmo, não como movimentos estanques, mas complementares. No início dos anos 80, com a morte de Foucault, Barthes, Althusser, Lacan e outros pensadores, o estruturalismo é abalado e questões fundamentais começaram a ser revistas. A forte relação entre $\mathrm{AD}$ e marxismo da primeira fase parece justificar o silêncio de Pêcheux acerca da relação entre $\mathrm{AD}$ e Psicanálise, que está explicitamente reconhecida atualmente, numa busca de melhor explicar os fenômenos discursivos.

Como exigência para essa nova visão da $\mathrm{AD}$, Pêcheux coloca alguns pontos:

- Descrição das materialidades discursivas (a língua);

- Relação mais específica da lingüística com a psicanálise, através dos nomes de Jakobson e Lacan;

- Pesquisa lingüística com abordagem do próprio da língua através do papel do equívoco, da elipse, da falta, etc.

Delineava-se, para a terceira fase da $\mathrm{AD}$, a noção de discurso que é constituído, ao mesmo tempo, por regularidades (estrutura) e por singularidades (acontecimentos), por um movimento em que o mesmo e o outro coexistem em um mesmo ambiente. Mas, questiona Nóbrega (2002), na quinta página de seu artigo, quem já tinha visto esta realidade na língua, quando o estável suporta, sempre, a instabilidade? E responde que Saussure assim o fizera. No entanto, pode-se dizer que essa similaridade, levantada pela autora, tem bases diferentes, pois a idéia de regularidade e singularidade em Saussure refere-se ao aspecto estrutural, enquanto em Pêcheux, ao aspecto histórico e psicanalítico. 


\section{NAS CONSIDERAÇÕES FINAIS, A FRAGMENTAÇÃO DO SUJEITO}

Pêcheux, em suas formulações iniciais de 1969, considera o sujeito como "um lugar determinado na estrutura social" (Gadet \& Hak, 1997, p. 82), algo diferente da presença física de organismos humanos individuais. Assim, esses sujeitos estão representados nos processos discursivos em que são colocados em jogo, por uma série de formações imaginárias que designam o lugar que destinador e destinatário se atribuem cada um a si e ao outro. Portanto, como aponta Indursky (2000, p. 70), o sujeito da $\mathrm{AD}$ é social sem consideração com sua condição lingüística e/ou individual.

Já em 1975, Pêcheux e Fuchs falam em uma teoria da subjetividade, de natureza psicanalítica. O sujeito da AD deixa de ser apenas social e ao seu conceito é agregado o inconsciente. Então o sujeito passa a atuar, pela teoria da $\mathrm{AD}$ sob o efeito de duas ilusões: pensa ser a fonte de seu dizer e o responsável pelo que diz.

No mesmo ano, Pêcheux (apud Indursky, 2000, p. 70), formula uma teoria não subjetiva da subjetividade, em que se articulam inconsciente e ideologia, ou seja, segundo ele, "os processos de imposição/ dissimulação que constituem o sujeito situamno", significando para o sujeito o que ele é e, ao mesmo tempo, dissimulam para ele essa situação (assujeitamento) pela ilusão de autonomia constitutiva do sujeito.

Portanto, o sujeito para Pêcheux é social, histórico, ideológico e dotado de inconsciente (a relação com o dizer do outro). Isso significa que o sujeito é afetado em seu funcionamento psíquico pelo inconsciente e em seu funcionamento social pela ideologia. Pêcheux (1998, p. 133) diz mais: "o recalque inconsciente e o assujeitamento ideológico estão materialmente ligados, sem estar confundidos, no interior do que se poderia designar como o processo do Significante na interpelação e na identificação”. Para o autor o caráter comum dessas duas estruturas consiste em dissimular sua própria existência no interior de seu funcionamento, produzindo um tecido de evidências "subjetivas". Daí a AD centrar seu interesse nas diferentes formas de representação do sujeito. Interfere aqui a noção de formação discursiva. É através da relação sujeito versus formação discursiva que se chega ao funcionamento do sujeito do discurso, pois a interpelação do sujeito em sujeito de seu discurso se efetua pela identificação desse mesmo sujeito com a formação discursiva que o domina (na qual ele é constituído como sujeito). Pêcheux diz ainda que essa identificação ocorre pelo viés da forma-sujeito (isto é, com o sujeito histórico dentro de uma formação discursiva que organiza seu dizer). É a forma sujeito regula o que pode e deve ser dito, conforme Pêcheux, e o que não pode ser dito ou que pode, mas não convém que seja dito em uma FD.

Vê-se, assim, a transformação do conceito de sujeito na $\mathrm{AD}$ : de "um lugar determinado na estrutura social" (Pêcheux, 1969), passou a ser, além de social, também dotado de inconsciente (Pêcheux e Fuchs, 1975) e, por fim, com a teoria não subjetiva da subjetividade, proposta por Pêcheux em Semântica e Discurso (1988), amplia-se para a forma-sujeito, também chamado de sujeito do saber, sujeito universal ou sujeito histórico de uma determinada formação discursiva, sendo responsável pela ilusão de unidade do sujeito. Então a forma-sujeito é social, histórica, ideológica e dotada de inconsciente, sendo duplamente afetada: pelo inconsciente e pela ideologia.

Mais tarde, Pêcheux introduz a noção de posição-sujeito, que, conforme definição de Ferreira (2001, p. 21), "é a relação estabelecida entre o sujeito do discurso e a forma-sujeito de uma dada formação discursiva". Uma posição sujeito não é uma realidade física, mas um objeto imaginário, representando no processo discursivo os lugares ocupados pelos sujeitos na estrutura de uma formação social. Desse modo, não 
há um sujeito único, mas diversas posições de sujeito, as quais estão relacionadas com determinadas formações discursivas e ideológicas. Surgem, então, as modalidades de tomada de posição.

Conforme lê-se em Indursky (2000, p.72) a primeira modalidade a que Pêcheux se refere sugere, ingenuamente, uma identificação plena, superposição entre o sujeito do discurso e o sujeito universal - é o discurso do bom sujeito que reflete espontaneamente a forma-sujeito da FD.

A segunda modalidade caracteriza o discurso do mau sujeito, em que o sujeito do discurso se contrapõe ao sujeito universal. É a instauração da diferença e da contradição na FD e na forma-sujeito.

Acrescenta-se a essas duas possibilidades de modalidades de tomada de posição, uma terceira, quando há desidentificação, deslocamento da identificação para outra FD adversa. Ocorre aí o deslizamento de uma forma de subjetivização para outra, dentro de um complexo de formações discursivas com dominante - o interdiscurso. Isso significa que a desidentificação em relação à forma-sujeito dominante (na terceira modalidade) conduz à operação de identificação com alguma outra forma-sujeito não dominante. Pode-se deduzir que, se há um complexo de formações discursivas ligadas entre si, há igualmente um complexo de formas-sujeito também ligadas entre si e a desidentificação conduz à operação de identificação com alguma dessas outras formas-sujeito secundárias.

Portanto, a forma-sujeito não pode mais ser concebida apenas como um bloco uniforme e homogêneo, tal como a primeira modalidade de tomada de posição preconiza, não há mais espaço apenas para a plena identificação com a forma-sujeito, que resulta no retorno ao mesmo e na reduplicação da identificação. $O$ trabalho na e sobre a forma-sujeito, decorrente da contra-identificação, resulta na tomada de posições discordantes. Em outras palavras, a forma-sujeito não pode mais ser observada sob a ótica da unicidade e para refletir sobre a forma-sujeito, é preciso considerar o seu desdobramento.

Tal acréscimo teórico na concepção da forma-sujeito tem como conseqüência permitir a instauração da diferença e da desigualdade de saberes dentro de uma mesma formação discursiva. Há, inclusive, uma redefinição das noções de FD e de ideologia: "uma ideologia não é idêntica a si mesma, só existe sob a modalidade da divisão, e não se realiza a não ser na contradição que com ela organiza a unidade e a luta dos contrários", como cita Indursky (2000, p. 75), ao referir-se ao texto "Remontémonos de Foucault a Spinoza", de Pêcheux.

Logo, a partir de uma FD heterogênea, a forma-sujeito sofre um desdobramento em diferentes posições-sujeito, que evidenciam diferentes formas de se relacionar com a forma-sujeito e com a ideologia. Uma forma-sujeito assim fragmentada devido à dispersão das posições-sujeito abre espaço tanto para saberes de natureza semelhantes (o parafrástico e homogêneo) como para sentidos divergentes e contraditórios (o polissêmico e heterogêneo).

Percebe-se que Pêcheux, embora não faça referência, aproxima-se da dialogia bakhtiniana, ao declarar que os modos de o sujeito identificar-se com a forma-sujeito vão de pequenas diferenças até grandes desigualdades que marcam o primado do outro sobre o mesmo, colocando em cena o discurso-outro imbricado ao discurso do sujeito.

Diz Indurky (ibid., p. 77) que a forma-sujeito, ao fragmentar-se, só pode ser percebida em sua totalidade pelo analista. Portanto, a análise, em AD, é responsável pela formulação e evolução dos conceitos e noções teóricas com que a teoria do 
discurso opera. Mas se pensarmos que o próprio analista do discurso, também deve estar inserido numa FD, como se inferir a possibilidade de um lugar especial, de observador e crítico, ocupado por aquele que têm maior contato com FDs divergentes e transita por elas, imune à sua contaminação? É possível isso?

Como se vê, a reflexão sobre $\mathrm{AD}$ é interminável, com suas possibilidades de contradição e permeabilidade. Então, deve-se curvar o pesquisador à relativa condição de sua visão. Conclui-se com a definição de Ferreira (2001, p. 11), buscando sintetizar a teoria desenvolvida ao longo desse artigo:

\begin{abstract}
Análise do Discurso é uma disciplina de entremeio (Orlandi, 1996) que se estrutura no espaço que há entre a lingüística e as ciências das formações sociais. Trabalha com as relações de contradição que se estabelecem entre essas disciplinas, caracterizando-se, não pelo aproveitamento de seus conceitos, mas por repensá-los, questionando na lingüística a negação da historicidade inscrita na linguagem e, nas ciências das formações sociais, a noção de transparência da linguagem sobre a qual se assentam as teorias produzidas nestas áreas. A AD nos permite trabalhar em busca dos processos de produção do sentido e de suas determinações histórico-sociais. Isso implica o reconhecimento de que há uma historicidade inscrita na linguagem que não nos permite pensar na existência de um sentido literal, já posto, e nem mesmo que o sentido possa ser qualquer um, já que toda interpretação é regida por condições de produção. Essa disciplina propõe um deslocamento das noções de linguagem e sujeito que se dá a partir de um trabalho com a ideologia. Assim, passa-se a entender a linguagem enquanto produção social, considerando-se a exterioridade como constitutiva. O sujeito, por sua vez, deixa de ser centro e origem do seu discurso para ser entendido como uma construção polifônica, lugar de significação historicamente constituído.
\end{abstract}

\title{
REFERÊNCIAS
}

ALTHUSSER, Louis. Ideologia e aparelhos Ideológicos de Estado. In: ZIZEK, Slavo. Um mapa da ideologia. Trad. Ribeiro, Vera. Rio de Janeiro: Contraponto, 1996.

FERREIRA, Maria Cristina Leandro (coord.). Glossário de Termos do Discurso. Porto Alegre:UFRGS, Instituto de Letras, 2001. INDURSKY, Freda. Da anáfora textual à anáfora discursiva. In: Anais do $1^{\circ}$ Encontro do CelSul. Vol. No 2, 1997 (713 - 722).

.A análise do discurso e sua inserção no campo das ciências da linguagem. In: Cadernos do IL-UFRGS, n²0/dezembro de1998.

. A fragmentação do sujeito em Análise do Discurso. In: INDURSKY, F. \& CAMPOS, Maria do Carmo (org.) Ensaios,- Discurso, Memória, Identidade $n^{0} 15$, Porto Alegre: Editora Sagra Luzzato, 2000 (pp.70-81).

. Da heterogeneidade do discurso à heterogeneidade do texto e sua implicações no processo da leitura. In: PEREIRA, A.\& FUNCK, S. (org.). A Leitura e a Escrita como Práticas Discursivas. Pelotas: Educat, 2001.

NÓBREGA, M. O mesmo e o outro: Saussure e a AD. In: Letras de Hoje, 2002.

ORLANDI, E. A análise de discurso: algumas observações. In: D.E.L.T.A., Vol. 2, n ${ }^{\mathrm{o}} 1$, $1986(105-126)$

. Linguagem e seu funcionamento - as formas do discurso. 2 ed..São Paulo: Pontes, 1987, (p.157-161; 180-181; 194-197; 229-230).

ORLANDI, E. Análise de Discurso - Princípios \& Procedimentos. 3 ed..São Paulo: Pontes, 2001. 
PÊCHEUX, M. Semântica e discurso: uma crítica à afirmação do óbvio. Trad. Orlandi, E. P. 2 ed. Campinas: UNICAMP, 1995.

. O discurso - estrutura ou acontecimento. Trad. Orlandi, E. P. 2 ed. Campinas: Pontes, 1997.

PÊCHEUX \& FUCHS. A propósito da análise automática do discurso: atualização e perspectivas (1975). In: GADET e HAK. Por uma análise automática do discurso Uma introdução à obra de Michel Pêcheux. Campinas: Ed. da UNICAMP. 1997, (p.163-179). 